\title{
Editorial
}

\section{La Gastronomía Primer Laboratorio de la Ciencia}

"No hay amor más sincero que el amor a la cocina."

Bernard George (1854)

En la construcción de establecer un escenario donde se reconozca el valor de la comida dentro de los contextos de la humanidad, la revista Sosquua en la presente edición quiere dar a conocer a sus lectores el papel que ha tenido la elaboración de productos alimentarios; dentro de los diversos cambios que el hombre ha tenido en la evolución de su conocimiento, evidenciando la importancia de reconocer el trabajo del gastrónomo como agente constructor del buen comer.

Para ello es importante reflexionar que el primer laboratorio en donde experimento el ser humano fue la cocina, en ella encontró el espacio de poder colocar en practica la mezcla de ingredientes, la manipulación de tipos de cocción y la forma de composición con que se emplata las diversas propuestas culinarias, que buscan satisfacer los diversos gustos de los comensales, para ello es fundamental reconocer la cultura de la región además los diversos elementos tipográficos de la población; que se busca impactar con la generación de ofertas gastronómicas.

De nuevo Sosquua Revista Especializada en Gastronomía, quiere convertirse en plataforma de debate investigativo, permitiendo que diversas indagaciones realizadas entorno al espacio culinario puedan dar a conocer diferentes puntos de vista, que ayuden en la construcción de una identidad gastronómica nacional a partir de experiencias obtenidas por diversos investigadores de diferentes áreas del saber, que ayuden analizar el rol del profesional en cocina.

Los invitamos a que nos acompañen con esta nueva experiencia del conocimiento, donde las reflexiones expuestas en este número, despierten las diversas sensaciones que posee la gastronomía en el escenario de la vida humana.

Royer Yesid Gutiérrez Quecano

Editor

Grupo de investigación Patrimonio Cultural Gastronómico de Colombia

Fundación Universitaria San Mateo 